\title{
Young age and high BMI are predictors of early revision surgery after primary anterior cruciate ligament reconstruction: a cohort study from the Swedish and Norwegian knee ligament registries based on 30,747 patients
}

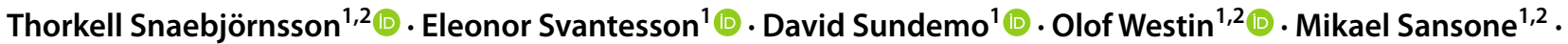 \\ Lars Engebretsen ${ }^{4}$ (C) Eric Hamrin-Senorski ${ }^{3}$ (i)
}

Received: 22 December 2018 / Accepted: 11 March 2019 / Published online: 16 March 2019

(c) The Author(s) 2019

\begin{abstract}
Purpose To analyse patient-related risk factors for 2-year ACL revision after primary reconstruction. The hypothesis was that younger athletes would have a higher incidence of an early ACL revision.

Methods This prospective cohort study was based on data from the Norwegian and Swedish National Knee Ligament Registries and included patients who underwent primary ACL reconstruction from 2004 to 2014. The primary end-point was the 2-year incidence of ACL revision. The impact of activity at the time of injury, patient sex, age, height, weight, BMI, and tobacco usage on the incidence of early ACL revision were described by relative risks (RR) with $95 \%$ confidence intervals (CI).

Results A total of 58,692 patients were evaluated for eligibility and 30,591 patients were included in the study. The mean incidence of ACL revision within 2 years was 2.82\% (95\% CI 2.64-3.02\%). Young age (13-19) was associated with an increased risk of early ACL revision (males $\mathrm{RR}=1.54$ [95\% CI 1.27-1.86] $p<0.001$ and females $\mathrm{RR}=1.58$ [95\% CI 1.28 1.96] $p<0.001$ ). Females over $1 \mathrm{SD}$ in weight ran an increased risk of early ACL revision ( $\mathrm{RR}=1.82$, [95\% CI 1.15-2.88] $p=0.0099$ ). Individuals with a BMI of over 25 ran an increased risk of early ACL revision (males: $\mathrm{RR}=1.78,[95 \% \mathrm{CI}$ 1.38-2.30] $p<0.001$ and females: $\mathrm{RR}=1.84$, [95\% CI 1.29-2.63] $p=0.008$ ).

Conclusion Young age, a BMI over 25, and overweight females were risk factors for an early ACL revision. Level of evidence II.
\end{abstract}

Keywords Anterior cruciate ligament $\cdot$ Reconstruction $\cdot$ Revision $\cdot$ Autograft $\cdot$ Registry $\cdot$ Gender $\cdot$ Body height $\cdot$ Body weight $\cdot$ Body mass index $\cdot$ Smoking $\cdot$ Smokeless tobacco $\cdot$ Graft failure

\section{Introduction}

Thorkell Snaebjörnsson

thorkellsn@gmail.com

1 Department of Orthopaedics, Institute of Clinical Sciences, The Sahlgrenska Academy, University of Gothenburg, Gothenburg, Sweden

2 Department of Orthopaedics, Sahlgrenska University Hospital, Mölndal, Sweden

3 Department of Health and Rehabilitation, Institute of Neuroscience and Physiology, The Sahlgrenska Academy, University of Gothenburg, Gothenburg, Sweden

4 University of Oslo, Oslo University Hospital, Oslo, Norway
Graft failure after surgical reconstruction of the anterior cruciate ligament (ACL) is a known complication. The previous studies have identified patient age [1-4], tobacco use [5], and participation in sports at competitive level $[4,6,7]$ as risk factors for revision ACL reconstruction. Data from the Scandinavian registries have previously been used in similar studies $[8,9]$ and these data are a valuable asset in identifying risk factors for revision surgery $[10,11]$.

Patients sustaining an ACL injury after playing football $[9,12]$ at a young age have been shown to run a higher risk of early ACL revision after primary reconstruction, while participation in other sports has not been as strongly 
associated with an ACL injury [13]. A large proportion of reruptures are known to occur within 2 years of the primary reconstruction $[14,15]$. It has, therefore, been suggested that return to sport should be delayed until 12-24 months after the primary ACL reconstruction [16].

Increased knowledge of how patient-related factors impact on the risk of ACL revision is important to be able to individualise treatment and target modifiable factors associated with increased risk.

In this prospective cohort study, we aimed to determine the effect of patient-related variables (activity at the time of injury, age, patient gender, height, weight and body mass index (BMI), smoking, and the usage of smokeless tobacco) on revision ACL reconstruction within 2 years of the primary ACL reconstruction. The hypothesis of this study was that younger patients would have a higher incidence of early ACL revision.

\section{Materials and methods}

Data were extracted from the Swedish National Knee Ligament Registry (SNKLR) and the Norwegian Knee Ligament Registry (NKLR). Patients eligible for inclusion were registered for primary ACL reconstruction from 2004 (Norway) and 2005 (Sweden) to 31 December 2014. The inclusion criteria were age between 13 and 59 years of age at the reconstruction, and ACL reconstruction performed with hamstring tendon (HT) or patella tendon (PT) autografts. All patients were followed for 2 years. Patients who underwent contralateral ACL reconstruction during the study period or had sustained concomitant bone, vascular or other ligament damage were excluded from the study.

\section{The Norwegian and Swedish National Knee Ligament Registries}

The NKLR was initiated in 2004 and the SNKLR in 2005 [17]. Data are collected prospectively and the estimated coverage of primary ACL reconstructions in the registries is close to 90\% [18] in Sweden and 86\% [19] in Norway. Surgical data, including primary and revision ACL reconstruction, are registered by the treating surgeon. Patients are identified by their unique social security number [20]. Follow-up using the Knee injury and Osteoarthritis Outcome Score (KOOS) is carried out by both registries. This is done preoperatively and, in Norway 2-, 5-, and 10-year postoperatively, while, in Sweden, follow-up takes place $1-, 2-, 5-$, and 10-year postoperatively $[17,18,21]$.

\section{Variables}

The current study investigated the following eight variables: sports activity at the time of primary ACL injury, patient sex, patient age, body height, body weight, BMI, cigarette smoking, and the usage of smokeless tobacco. In the SNKLR and NKLR, data on activity at the time of injury are available. Body mass index was categorised as underweight $\left(<18.5 \mathrm{~kg} / \mathrm{m}^{2}\right)$, normal range $(18.5-24.9 \mathrm{~kg} /$ $\mathrm{m}^{2}$ ), overweight $\left(25.0-29.9 \mathrm{~kg} / \mathrm{m}^{2}\right)$, and obese $(\geq 30.0 \mathrm{~kg} /$ $\mathrm{m}^{2}$ ), according to the World Health Organization [22]. A statistical analysis of BMI was adjusted by dividing the group in two; one group of patients who were 20 years of age or older, and one with patients 19 years of age or younger. This was done because of extensive changes in BMI from birth through early adulthood [23]. Body height and body weight were stratified according to the central limit theorem and divided into sexes. Data analyses for demographics and anthropometry were made separately for men and women.

\section{Outcome measurements}

The primary end-point in this study was the 2-year cumulative incidence of ACL revision surgery, defined as the occurrence of new ipsilateral ACL reconstruction within 2 years of the primary ACL reconstruction. Follow-up began on the same day as the primary ACL reconstruction was performed and the end-point was either 2 years of follow-up or revision surgery, whichever occurred first.

The regional ethical review board in Stockholm, Sweden, approved the research (ID 2011/337-31/3).

In Norway, informed consent is obtained for all patients [21].

During the study period, access was bound to unidentifiable data from the database. Data from the NKLR were treated according to Norwegian legislation [21].

\section{Statistical analysis}

Data files from the SNKLR and NKLR were combined and statistical analyses were performed using the SAS System for Windows, version 9; SAS Institute, Cary, North Carolina, USA.

Descriptive statistics for patient demographics were reported as numbers and percentages for categorical variables.

Continuous variables were reported as the mean, standard deviation, median, minimum, and maximum.

The impact of activity at the time of injury, age, patient sex, height, weight and BMI, smoking, and the usage of smokeless tobacco on the incidence of ACL revision was 
reported as relative risks (RR) with $95 \%$ confidence intervals (CI) estimated using generalised linear models with binomial distribution and log-link function. Adjustments for known confounders were made using multivariable analysis; adjusting for age, graft diameter, graft type, fixation in the tibia and femur, meniscal injury and cartilage injury, time to surgery, and country. All tests were two-sided and conducted at the 5\% significance level. Statistical significance was defined as a $95 \%$ CI for risk estimates not including 1.00 and $p<0.05$.

\section{Results}

A total of 58,692 individuals were identified in the SNKLR and NKRL during the study period and examined for eligibility (Fig. 1). A total of 30,591 individuals $(17,446$ males and 13,145 females) were included (Table 1). A total of 20,546 patients originated from Sweden, while
10,045 came from Norway. A total of 864 individuals had undergone ACL revision within 2 years of the primary ACL reconstruction, corresponding to a crude revision rate of $2.82 \%$.

\section{Activity at the time of the injury}

A total of 13,673 patients played football at the time of injury. This activity was the most common sport for men (52.8\%), while floorball (6.9\%) was second (Table 2). Males playing floorball at the time of the ACL injury ran a significantly lower risk of early ACL revision compared with all other sports. For women, football (34.4\%) was also the most common activity, with handball (16.2\%) being second (Table 2). Females who sustained an ACL injury, while downhill skiing ran a significantly lower risk of early ACL revision when compared with females participating in other sports when the ACL injury occurred.
Fig. 1 Flow chart of inclusion and exclusion criteria

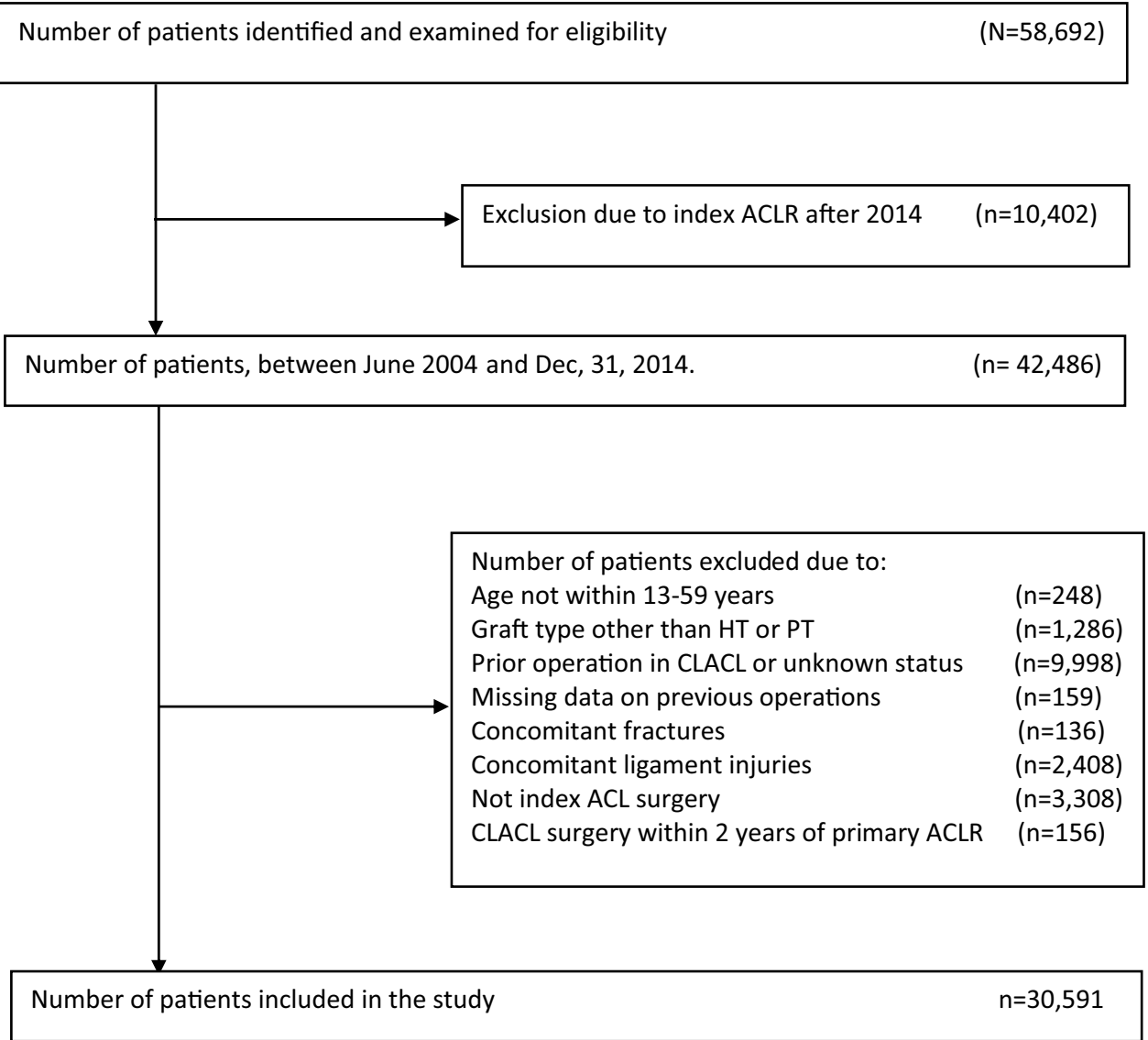

* N, number; ACL, anterior cruciate ligament; ACLR, anterior cruciate ligament reconstruction; CLACL contralateral anterior cruciate ligament; HT, hamstring tendon; PT, patella tendon 


\section{Patient sex}

There was no significant difference between men and women in the risk of early ACL revision (Table 3).

\section{Age}

The study participants were stratified into three different age groups (Table 4). For males, the adolescents (13-19 years of age) had significantly increased risk of ACL revision within

Table 1 Baseline demographics

\begin{tabular}{lccc}
\hline & Total $(n=30,591)$ & Males $(n=17,446)$ & Females $(n=13,145)$ \\
\hline Age at index ACL injury & $24.4(9.2)$ & $25.2(8.5)$ & $23.2(9.9)$ \\
Age at index ACLR & $26.5(9.7)$ & $27.5(9.0)$ & $25.1(10.4)$ \\
Adolescents & $9430(30.8 \%)$ & $3755(21.5 \%)$ & $5675(43.2 \%)$ \\
Height & $174.7(9.1)$ & $180.5(6.6)$ & $167.6(6.1)$ \\
Weight & $75.6(14.2)$ & $82.5(12.1)$ & $67.1(11.8)$ \\
Body mass index & $24.7(3.6)$ & $25.3(3.3)$ & $23.9(3.9)$ \\
Smokers & $1732(11.7 \%)$ & $1003(12.3 \%)$ & $729(11.0 \%)$ \\
Smokeless tobacco users & $1820(15.0 \%)$ & $1530(22.9 \%)$ & $290(5.3 \%)$ \\
HT autograft & $26,537(86.7 \%)$ & $15,039(86.2 \%)$ & $11,498(87.5 \%)$ \\
Surgery duration & $74.5(24.2)$ & $75.1(24.3)$ & $73.6(24.0)$ \\
Injury-to-surgery (months) & $17.2(31.0)$ & $17.3(30.4)$ & $17.1(31.9)$ \\
Meniscal injury & $10,958(42.4 \%)$ & $6755(44.8 \%)$ & $4203(39.1 \%)$ \\
Cartilage injury & $7033(27.2 \%)$ & $4441(29.5 \%)$ & $2592(24.1 \%)$ \\
Activity & & & $4501(34.4 \%)$ \\
Soccer/football & $13,673(44.9 \%)$ & $9172(52.8 \%)$ & $713(5.5 \%)$ \\
Floorball & $1916(6.3 \%)$ & $1203(6.9 \%)$ & $2120(16.2 \%)$ \\
Handball & $2718(8.95 \%)$ & $598(3.4 \%)$ & $1399(10.7 \%)$ \\
Alpine skiing & $2435(8.0 \%)$ & $1036(6.0 \%)$ & \\
\hline
\end{tabular}

For categorical variables $n(\%)$ is presented, while, for continuous variables, the mean (SD) is presented $A C L$ anterior cruciate ligament, ACLR anterior cruciate ligament reconstruction, HT hamstring tendon, adolescents, 13-19 years of age

Table 2 Incidence of revision surgery within 2 years, activity at the time of ACL injury

\begin{tabular}{|c|c|c|c|c|c|c|c|c|}
\hline \multirow[t]{2}{*}{ Activity } & \multicolumn{4}{|l|}{ Men } & \multicolumn{4}{|l|}{ Women } \\
\hline & Incidence (\%) & Adjusted RR & $95 \% \mathrm{CI}$ & $p$ value & Incidence (\%) & Adjusted RR & $95 \%$ CI & $p$ value \\
\hline Football & 3.07 & 1.09 & $0.91-1.30$ & n.s. & 2.98 & 0.95 & $0.76-1.19$ & n.s. \\
\hline Floorball & 1.25 & 0.47 & $0.28-0.79$ & 0.0048 & 2.24 & 0.81 & $0.52-1.41$ & n.s. \\
\hline Skiing ${ }^{\mathrm{a}}$ & 1.54 & 0.67 & $0.41-1.09$ & n.s. & 0.71 & 0.33 & $0.17-0.60$ & 0.0005 \\
\hline Handball & 4.01 & 1.15 & $0.78-1.70$ & n.s. & 4.1 & 1.25 & $0.97-1.60$ & n.s. \\
\hline
\end{tabular}

Adjusted for age, time to surgery, graft type, graft diameter, femoral fixation (cortical, cross/rigid, metal screw, bioabsorbable screw), tibial fixation (post, bioabsorbable screw), concomitant meniscal injury, concomitant cartilage injury, and country

$A C L$ anterior cruciate ligament, $R R$ relative risk, $C I$ confidence interval

${ }^{a}$ Downhill skiing

Table 3 Revision surgery within 2 years, men versus women

\begin{tabular}{|c|c|c|c|c|c|c|c|}
\hline \multirow[t]{2}{*}{ Activity } & \multirow[t]{2}{*}{ Incidence $\%$} & \multicolumn{3}{|c|}{ Unadjusted } & \multicolumn{3}{|c|}{ Adjusted $^{\mathrm{a}}$} \\
\hline & & $\mathrm{RR}$ & $95 \% \mathrm{CI}$ & $p$ value & $\mathrm{RR}$ & $95 \% \mathrm{CI}$ & $p$ value \\
\hline Patient sex & 2.83 versus 2.82 & 1 & $0.88-1.14$ & n.s. & 1.13 & $0.98-1.29$ & n.s. \\
\hline
\end{tabular}

$R R$ relative risk, $C I$ confidence interval

${ }^{a}$ Adjusted for age, time to surgery, graft type, graft diameter, femoral fixation, tibia fixation, concomitant meniscal injury, concomitant cartilage injury, and country 
2 years of the primary reconstruction compared with all the others, while the oldest age group ran a reduced risk of early ACL revision compared with all other age groups. Within the female group, the youngest age group ran an increased risk of compared with all older females. Both the other age groups, 20-29 and 30-59 years of age, ran a reduced risk of revision when compared with all the other female age groups.

\section{Anthropometric data}

No significant differences in early ACL revision were found when analysing the effect of patient height (Table 5). For women weighing more than one standard deviation over the mean weight (Table 6), there was an increased risk of early ACL revision when compared with all other women.

When combining height and weight in BMI for patients 20 years of age or older (Table 7), the results were similar for both men and women. Participants with a BMI of under
25 ran a significantly lower risk of early ACL revision compared with the rest of the study group. Participants with a BMI of 25 or more ran an increased risk of an early $\mathrm{ACL}$ revision compared with patients with a BMI of under 25 . More specifically, men with a BMI of between 25 and 30 ran an increased risk of early ACL revision when compared with all other men. Women with a BMI of between 25 and 30 also ran an increased risk of ACL revision when compared with all other women. Patients with a BMI of over 30 did not show any increased risk of early ACL revision compared with all other groups.

The effect of BMI on the risk of ACL revision for patients 19 years of age or younger (Table 8) was similar to older patients. For men, those with a BMI of between 25 and 30 ran an increased risk of revision compared with all other men. All women 19 years of age or younger with a BMI of over 25 ran an increased risk of revision compared with all other women.
Table 4 Incidence of revision surgery within 2 years, age at the time of ACL reconstruction

\begin{tabular}{|c|c|c|c|c|c|c|c|c|}
\hline \multirow[t]{2}{*}{ Age } & \multicolumn{4}{|l|}{ Men } & \multicolumn{4}{|l|}{ Women } \\
\hline & Incidence (\%) & Adjusted RR & $95 \% \mathrm{CI}$ & $p$ value & Incidence & Adjusted RR & $95 \% \mathrm{CI}$ & $p$ value \\
\hline $13-19$ & 3.97 & 1.52 & $1.26-1.84$ & $<0.001$ & 3.65 & 1.58 & $1.28-1.95$ & $<0.001$ \\
\hline $20-29$ & 2.8 & 1 & $0.84-1.20$ & n.s. & 2.25 & 0.73 & $0.57-0.93$ & 0.012 \\
\hline $30-59$ & 2.17 & 0.66 & $0.54-0.81$ & $<0.001$ & 2.14 & 0.75 & $0.58-0.97$ & 0.030 \\
\hline
\end{tabular}

Adjusted for time to surgery, graft type, graft diameter, femoral fixation, tibia fixation, concomitant meniscal injury, concomitant cartilage injury, and country

$A C L$ anterior cruciate ligament, $R R$ relative risk, $C I$ confidence interval

Table 5 Incidence of revision surgery within 2 years, height

\begin{tabular}{|c|c|c|c|c|c|c|c|c|}
\hline \multirow[t]{2}{*}{ Height } & \multicolumn{4}{|l|}{ Men } & \multicolumn{4}{|l|}{ Women } \\
\hline & Incidence $(\%)$ & Adjusted RR & $95 \% \mathrm{CI}$ & $p$ value & Incidence (\%) & Adjusted RR & $95 \% \mathrm{CI}$ & $\overline{p \text { value }}$ \\
\hline$<-1 \mathrm{SD}$ & 2.09 & 1.1 & $0.69-1.76$ & n.s. & 2.18 & 0.91 & $0.56-1.49$ & n.s. \\
\hline $\pm 1 \mathrm{SD}$ & 1.82 & 0.82 & $0.57-1.18$ & n.s. & 2.25 & 0.84 & $0.59-1.19$ & n.s. \\
\hline$>1 \mathrm{SD}$ & 2.35 & 1.27 & $0.80-2.00$ & n.s. & 3.21 & 1.4 & $0.93-2.11$ & n.s. \\
\hline
\end{tabular}

Adjusted for age, graft diameter, femoral fixation, country

$R R$ relative risk, $C I$ confidence interval, $S D$ standard deviation

Table 6 Incidence of revision surgery within 2 years, weight

\begin{tabular}{|c|c|c|c|c|c|c|c|c|}
\hline \multirow[t]{2}{*}{ Weight } & \multicolumn{4}{|l|}{ Men } & \multicolumn{4}{|l|}{ Women } \\
\hline & Incidence $(\%)$ & Adjusted $^{\mathrm{a}} \mathrm{RR}$ & $95 \% \mathrm{CI}$ & $p$ value & Incidence $(\%)$ & Adjusted $^{\mathrm{a}} \mathrm{RR}$ & $95 \% \mathrm{CI}$ & $p$ value \\
\hline$<-1 \mathrm{SD}$ & 2.49 & 1.09 & $0.69-1.73$ & n.s. & 2.03 & 0.77 & $0.43-1.36$ & n.s. \\
\hline $\pm 1 \mathrm{SD}$ & 1.89 & 0.86 & $0.59-1.26$ & n.s. & 2.29 & 0.8 & $0.54-1.17$ & n.s. \\
\hline$>1 \mathrm{SD}$ & 1.83 & 1.21 & $0.70-2.11$ & n.s. & 3.3 & 1.82 & $1.16-2.88$ & 0.0099 \\
\hline
\end{tabular}

$R R$ relative risk, $C I$ confidence interval, $S D$ standard deviation

${ }^{a}$ Adjusted for age, time to surgery, graft type, graft diameter, femoral fixation, concomitant meniscus injury, concomitant cartilage injury, and country 


\section{Tobacco use}

The use of either tobacco or smokeless tobacco for patients undergoing primary ACL reconstruction was not a risk factor for early ACL revision (Table 9) when compared with patients not using tobacco or smokeless tobacco.

\section{High-risk individuals}

A further analysis was performed for adolescents who played football at the time of the injury. Young football players ran a significantly increased risk of early ACL revision (Table 10) among both men and women.

\section{Discussion}

The most important finding in this study was that adolescents run an increased risk of early ACL revision. Female downhill skiers and male floorball players ran an increased risk of early ACL revision compared with other sports. Individuals with a BMI at either end $(18<25$ and $\geq 30)$ of the BMI scale ran a lower risk of early ACL revision compared with those with a BMI of between 25 and 30. Adolescents playing football at the time of primary ACL injury ran a significantly increased risk of early ACL reconstruction among both men and women.

In the present study, playing floorball at the time of the ACL injury significantly decreased the risk of an early ACL

Table 7 Incidence of revision surgery within 2 years, adults BMI

\begin{tabular}{|c|c|c|c|c|c|c|c|c|}
\hline \multirow[t]{2}{*}{ BMI } & \multicolumn{4}{|l|}{ Men } & \multicolumn{4}{|l|}{ Women } \\
\hline & Incidence $(\%)$ & Adjusted $\mathrm{RR}^{\mathrm{a}}$ & $95 \% \mathrm{CI}$ & $p$ value & Incidence $(\%)$ & Adjusted $\mathrm{RR}^{\mathrm{a}}$ & $95 \% \mathrm{CI}$ & $p$ value \\
\hline $18.5<25$ & 2.24 & 0.57 & $0.44-0.73$ & $<0.001$ & 1.95 & 0.55 & $0.38-0.78$ & 0.009 \\
\hline$\geq 25$ & 4.21 & 1.74 & $1.35-2.24$ & $<0.001$ & 3.94 & 1.84 & $1.29-2.63$ & 0.008 \\
\hline 25 to $<30$ & 4.75 & 1.95 & $1.52-2.50$ & $<0.001$ & 4.37 & 1.90 & $1.33-2.71$ & 0.004 \\
\hline$\geq 30$ & 1.34 & 0.53 & $0.28-1.03$ & n.s. & 2.45 & 1 & $0.51-1.95$ & n.s. \\
\hline
\end{tabular}

Adults, aged 20 and above included

$R R$ relative risk, $C I$ confidence interval

${ }^{a}$ Adjusted for age, time to surgery, graft type, graft diameter, femoral fixation, tibia fixation, concomitant meniscal injury, concomitant cartilage injury, and country

Table 8 Incidence of revision surgery within 2 years, BMI adolescents

\begin{tabular}{|c|c|c|c|c|c|c|c|c|}
\hline \multirow[t]{2}{*}{ BMI } & \multicolumn{4}{|l|}{ Men } & \multicolumn{4}{|l|}{ Women } \\
\hline & Incidence (\%) & Adjusted RR & $95 \% \mathrm{CI}$ & $p$ value & Incidence $(\%)$ & Adjusted RR & $95 \% \mathrm{CI}$ & $p$ value \\
\hline $18.5<25$ & 3.74 & 0.66 & $0.44-0.99$ & 0.045 & 3.45 & 0.55 & $0.40-0.77$ & 0.0004 \\
\hline$\geq 25$ & 5.62 & 1.56 & $1.05-2.34$ & 0.030 & 5.68 & 1.77 & $1.29-2.52$ & 0.0006 \\
\hline 25 to $<30$ & 6.57 & 1.92 & $1.28-2.87$ & 0.0015 & 6.29 & 1.99 & $1.45-2.86$ & $<0.001$ \\
\hline$\geq 30$ & & & & & 1.56 & 0.43 & $0.10-1.67$ & n.s. \\
\hline
\end{tabular}

Adjusted for age, time to surgery, graft type, graft diameter, femoral fixation, tibia fixation, concomitant meniscal injury, concomitant cartilage injury, and country

Adolescents, aged 19 and below included

$R R$ relative risk, $C I$ confidence interval;

Table 9 Incidence of revision surgery within 2 years, tobacco use

\begin{tabular}{|c|c|c|c|c|c|c|c|c|}
\hline \multirow[t]{2}{*}{ Tobacco use } & \multicolumn{4}{|l|}{ Men } & \multicolumn{4}{|l|}{ Women } \\
\hline & Incidence (\%) & Adjusted RR & $95 \% \mathrm{CI}$ & $\overline{p \text { value }}$ & Incidence (\%) & Adjusted RR & $95 \% \mathrm{CI}$ & $\overline{p \text { value }}$ \\
\hline Smoking & 1.2 & 0.73 & $0.40-1.36$ & n.s. & 1.92 & 1.49 & $0.83-2.65$ & n.s. \\
\hline Non-smoking & 2.42 & 1.28 & $0.87-1.87$ & n.s. & 2.07 & 0.99 & $0.44-2.22$ & n.s. \\
\hline
\end{tabular}

Adjusted for age, time to surgery, graft type, graft diameter, femoral fixation, concomitant meniscal injury, concomitant cartilage injury, and country

$R R$ relative risk, $C I$ confidence interval 
Table 10 Incidence of revision surgery within 2 years, high-risk individuals

\begin{tabular}{|c|c|c|c|c|c|c|c|c|}
\hline \multirow[t]{2}{*}{ Activity } & \multicolumn{4}{|l|}{ Men } & \multicolumn{4}{|l|}{ Women } \\
\hline & Incidence $(\%)$ & Adjusted $^{\mathrm{a}} \mathrm{RR}$ & $95 \% \mathrm{CI}$ & $p$ value & Incidence $(\%)$ & Adjusted $^{\mathrm{a}} \mathrm{RR}$ & $95 \% \mathrm{CI}$ & $p$ value \\
\hline Risk group & 4.36 & 1.55 & $1.25-1.92$ & $<0.001$ & 3.96 & 1.49 & $1.18-1.87$ & 0.0007 \\
\hline
\end{tabular}

$R R$ relative risk, $C I$ confidence interval

${ }^{a}$ Adjusted for time to surgery, graft type, graft diameter, femoral fixation, tibia fixation, concomitant meniscal injury, concomitant cartilage injury, and country

revision in men compared with all other sporting and nonsporting activities at the time of the index injury. Floorball is played professionally in Sweden and, in a recent Swedish epidemiological study, [24] ACL injuries were much more frequent in women. For women, sustaining an ACL injury during downhill skiing reduced the risk of an early ACL revision when compared with all other activities at the time of the index injury. Interestingly, playing football was the most common activity that leads to injury for both men and women. This is in accordance with the previous studies in the field [17]. Unfortunately, no data are available about return to sport or the age or level of individuals suffering from ACL injuries in Scandinavian registries, on which the current study is based on. The type of sport and activity at the time of injury could have a significant impact on the incidence of early ACL revision, with a recent large-scale emphasis on appropriate readiness to return to sport criteria $[16,25]$.

\section{Patient gender}

Women are known to run a greater risk of ACL injuries compared with males, [26] with sex-related differences in knee and ankle kinematics [27] or even the timing of knee forces [28] as a possible explanation. Studies have been unable to identify any significant sex-specific difference in the incidence of graft failure after ACL reconstruction [29, 30]. The results of the present study further underline that there is no apparent sex-specific difference related to the incidence of early ACL revision.

\section{Age}

Adolescents (13-19 years of age) ran a significantly higher risk of early ACL revision compared with older age groups. Older women (both 20-29 and 30-59) ran a significantly reduced risk of revision compared with other women. Men between 30 and 59 years of age ran a significantly lower risk of early ACL revision compared with younger men.

These results are in line with multiple other studies indicating an increased risk of reinjury or revision ACL surgery for younger patients [7, 9, 31-34]. This can be partly explained by the higher activity level of younger athletes, returning early after rehabilitation [35], insufficient rehabilitation or the fact that a repeated ACL surgery after initial failure can be a less favorable alternative for older patients who are not attempting to return to their preinjury activity level.

\section{Anthropometric data}

The body weight was only found to be predictive for women who had more than $1 \mathrm{SD}$ over the average weight $[67.1$ (SD 11.8)] and BMI was a predictor of ACL revision. The results indicate that, when overweight $\left(25-30 \mathrm{~kg} / \mathrm{m}^{2}\right)$ and obese $\left(>30 \mathrm{~kg} / \mathrm{m}^{2}\right.$ ) patients are treated as one group, the patients run an increased risk of ACL revision. Similar results were found for women, 19 years of age or younger, and older patients of both sex. When dividing patients with a BMI of over 25 into two different groups, it is only the overweight group (BMI 25-30) and not the obese group (BMI $\geq 30$ ) that runs a significantly increased risk of revision surgery for all age groups. Biomechanical differences in terms of muscle control for patient groups differing in BMI [36] may play a part as well as the patients' level of participation in sport. Prior studies are inconclusive when it comes to the effect of $\mathrm{BMI}$ on ACL revision [37-39].

\section{Tobacco}

Tobacco use was not a risk factor for early ACL revision surgery. Patients using tobacco have significantly poorer subjective outcome measurements, as well as an increased risk of adverse events such as infection and VTE after ACL reconstruction, [5, 40], although the results have been inconclusive in terms of the risk of reinjury and subsequent ACL revision.

\section{High-risk individuals}

Football players were analysed further, because this is the largest subgroup of patients in the present study and adolescents run the highest risk of early ACL injury compared with older age groups. It is known that younger players and men [41] have greater success in terms of their ability to return to sport and football after ACL reconstruction [12, 
$25,42]$. The current results indicate a similar incidence of early ACL revision surgery for men compared with women among these high-risk individuals. It is noteworthy that previous studies [18] have specifically identified young female football players at increased risk of ACL revision surgery, which conflicts with the findings in this study.

\section{Limitations}

In the present study, only ACL revision was studied as an outcome. However, this underestimates the true occurrence of graft failure after primary reconstruction. Since the SNKLR and NKLR only register revision surgery and not graft failure, it was not possible to identify all patients suffering from graft failure. Patients with graft failure may choose not to undergo ACL revision for a number of reasons. This means that there is a possibility of different predictors of ACL revisions than of graft failures.

Bearing in mind the strict criteria for the end-point, we have avoided a discussion of how to confirm clinical graft failure, thereby making this study easier to compare and replicate.

\section{Conclusion}

Younger age, overweight women, and patients with BMI between 25 and 30 all run an increased risk of early ACL revision surgery after primary ACL reconstruction. Patient sex, tobacco use, and height were not shown to be significant risk factors for early ACL revision. Men playing floorball and women sustaining their ACL injury during downhill skiing run a reduced risk of early ACL revision compared with patients performing other activities at the time of injury.

Playing football and adolescence at the time of the primary ACL injury results in an increased risk of early ACL revision among both men and women.

Funding The corresponding author has received research support from Gothenburg medical Association (salaries for a total of 2 months).

\section{Compliance with ethical standards}

Conflict of interest Thorkell Snaebjörnsson has received research support from Gothenburg Medical Association. Lars Engebretsen has received fellowship and research support from Smith and Nephew, and fellowship and research support from Arthrex. All other authors declare no conflicts of interest.

Ethical approval The regional ethical review board in Stockholm, Sweden, approved the research (ID 2011/337-31/3).
Open Access This article is distributed under the terms of the Creative Commons Attribution 4.0 International License (http://creativeco mmons.org/licenses/by/4.0/), which permits unrestricted use, distribution, and reproduction in any medium, provided you give appropriate credit to the original author(s) and the source, provide a link to the Creative Commons license, and indicate if changes were made.

\section{References}

1. Fauno P, Rahr-Wagner L, Lind M (2014) Risk for revision after anterior cruciate ligament reconstruction is higher among adolescents: results from the danish registry of knee ligament reconstruction. Orthop J Sports Med 2:2325967114552405

2. Kamien PM, Hydrick JM, Replogle WH, Go LT, Barrett GR (2013) Age, graft size, and Tegner activity level as predictors of failure in anterior cruciate ligament reconstruction with hamstring autograft. Am J Sports Med 41:1808-1812

3. Maletis GB, Chen J, Inacio MC, Funahashi TT (2016) Agerelated risk factors for revision anterior cruciate ligament reconstruction: a cohort study of 21,304 patients from the kaiser permanent anterior cruciate ligament registry. Am J Sports Med 44:331-336

4. Yabroudi MA, Bjornsson H, Lynch AD, Muller B, Samuelsson K, Tarabichi M et al (2016) Predictors of revision surgery after primary anterior cruciate ligament reconstruction. Orthop J Sports Med 4:2325967116666039

5. Cancienne JM, Gwathmey FW, Miller MD, Werner BC (2016) Tobacco use is associated with increased complications after anterior cruciate ligament reconstruction. Am J Sports Med 44:99-104

6. Gans I, Retzky JS, Jones LC, Tanaka MJ (2018) Epidemiology of recurrent anterior cruciate ligament injuries in national collegiate athletic association sports: the injury surveillance program, 2004-2014. Orthop J Sports Med 6:2325967118777823

7. Kaeding CC, Pedroza AD, Reinke EK, Huston LJ, Spindler KP (2015) Risk factors and predictors of subsequent ACL injury in either knee after ACL reconstruction: prospective analysis of 2488 primary ACL reconstructions from the MOON cohort. Am J Sports Med 43:1583-1590

8. Andernord D, Bjornsson H, Petzold M, Eriksson BI, Forssblad M, Karlsson J et al (2014) Surgical predictors of early revision surgery after anterior cruciate ligament reconstruction: results from the Swedish National Knee ligament register on 13,102 patients. Am J Sports Med 42:1574-1582

9. Andernord D, Desai N, Björnsson H, Ylander M, Karlsson J, Samuelsson K (2015) Patient predictors of early revision surgery after anterior cruciate ligament reconstruction: a cohort study of 16,930 patients with 2-year follow-up. Am J Sports Med 43:121-127

10. Engebretsen L, Forssblad M (2009) Why knee ligament registries are important. Knee Surg Sports Traumatol Arthrosc 17:115-116

11. Svantesson E, Hamrin Senorski E, Baldari A, Ayeni OR, Engebretsen L, Franceschi $\mathrm{F}$ et al (2018) Factors associated with additional anterior cruciate ligament reconstruction and register comparison: a systematic review on the Scandinavian knee ligament registers. Br J Sports Med. https://doi.org/10.1136/bjsports2017-098192

12. Allen MM, Pareek A, Krych AJ, Hewett TE, Levy BA, Stuart MJ et al (2016) Are female soccer players at an increased risk of second anterior cruciate ligament injury compared with their athletic peers? Am J Sports Med 44:2492-2498

13. Gornitzky AL, Lott A, Yellin JL, Fabricant PD, Lawrence JT, Ganley TJ (2016) Sport-specific yearly risk and incidence of anterior cruciate ligament tears in high school athletes: a systematic review and meta-analysis. Am J Sports Med 44:2716-2723 
14. Faltstrom A, Hagglund M, Magnusson H, Forssblad M, Kvist J (2016) Predictors for additional anterior cruciate ligament reconstruction: data from the Swedish national ACL register. Knee Surg Sports Traumatol Arthrosc 24:885-894

15. Lind M, Menhert F, Pedersen AB (2012) Incidence and outcome after revision anterior cruciate ligament reconstruction: results from the Danish registry for knee ligament reconstructions. Am J Sports Med 40:1551-1557

16. Nagelli CV, Hewett TE (2017) Should return to sport be delayed until 2 years after anterior cruciate ligament reconstruction? Biological and functional considerations. Sports Med 47:221-232

17. Granan LP, Forssblad M, Lind M, Engebretsen L (2009) The Scandinavian ACL registries 2004-2007: baseline epidemiology. Acta Orthop 80:563-567

18. Ahlden M, Samuelsson K, Sernert N, Forssblad M, Karlsson J, Kartus J (2012) The Swedish National Anterior Cruciate Ligament Register: a report on baseline variables and outcomes of surgery for almost 18,000 patients. Am J Sports Med 40:2230-2235

19. Ytterstad K, Granan LP, Ytterstad B, Steindal K, Fjeldsgaard KA, Furnes O et al (2012) Registration rate in the Norwegian Cruciate Ligament Register: large-volume hospitals perform better. Acta Orthop 83:174-178

20. Lunde AS, Lundeborg S, Lettenstrom GS, Thygesen L, Huebner J (1980) The person-number systems of Sweden, Norway, Denmark, and Israel. Vital Health Stat 2:1-59

21. Granan LP, Bahr R, Steindal K, Furnes O, Engebretsen L (2008) Development of a national cruciate ligament surgery registry: the Norwegian National Knee Ligament Registry. Am J Sports Med $36: 308-315$

22. WHO (2000) Obesity: preventing and managing the global epidemic. Report of a WHO consultation. World Health Organ Tech Rep Ser 894:i-xii (1-253)

23. Prentice AM (1998) Body mass index standards for children. Are useful for clinicians but not yet for epidemiologists. BMJ 317:1401-1402

24. Tranaeus U, Gotesson E, Werner S (2016) Injury profile in swedish elite floorball. Sports Health 8:224-229

25. Webster KE, Feller JA (2018) Return to level I sports after anterior cruciate ligament reconstruction: evaluation of age, sex, and readiness to return criteria. Orthop J Sports Med 6:2325967118788045

26. Schilaty ND, Bates NA, Nagelli C, Krych AJ, Hewett TE (2018) Sex-based differences in knee kinetics with anterior cruciate ligament strain on cadaveric impact simulations. Orthop J Sports Med 6:2325967118761037

27. Ford KR, Myer GD, Toms HE, Hewett TE (2005) Gender differences in the kinematics of unanticipated cutting in young athletes. Med Sci Sports Exerc 37:124-129

28. Sigurethsson HB, Sveinsson T, Briem K (2018) Timing, not magnitude, of force may explain sex-dependent risk of ACL injury. Knee Surg Sports Traumatol Arthrosc 26:2424-2429

29. Noojin FK, Barrett GR, Hartzog CW, Nash CR (2000) Clinical comparison of intraarticular anterior cruciate ligament reconstruction using autogenous semitendinosus and gracilis tendons in men versus women. Am J Sports Med 28:783-789

30. Salmon L, Russell V, Musgrove T, Pinczewski L, Refshauge $\mathrm{K}$ (2005) Incidence and risk factors for graft rupture and contralateral rupture after anterior cruciate ligament reconstruction. Arthroscopy 21:948-957
31. Paterno MV, Rauh MJ, Schmitt LC, Ford KR, Hewett TE (2014) Incidence of second ACL injuries 2 years after primary ACL reconstruction and return to sport. Am J Sports Med 42:1567-1573

32. Webster KE, Feller JA (2016) Exploring the high reinjury rate in younger patients undergoing anterior cruciate ligament reconstruction. Am J Sports Med 44:2827-2832

33. Webster KE, Feller JA, Leigh WB, Richmond AK (2014) Younger patients are at increased risk for graft rupture and contralateral injury after anterior cruciate ligament reconstruction. Am J Sports Med 42:641-647

34. Wiggins AJ, Grandhi RK, Schneider DK, Stanfield D, Webster KE, Myer GD (2016) Risk of secondary injury in younger athletes after anterior cruciate ligament reconstruction: a systematic review and meta-analysis. Am J Sports Med 44:1861-1876

35. Grindem H, Snyder-Mackler L, Moksnes H, Engebretsen L, Risberg MA (2016) Simple decision rules can reduce reinjury risk by $84 \%$ after ACL reconstruction: the Delaware-Oslo ACL cohort study. Br J Sports Med 50:804-808

36. Hsu WH, Fan CH, Yu PA, Chen CL, Kuo LT, Hsu RW (2018) Effect of high body mass index on knee muscle strength and function after anterior cruciate ligament reconstruction using hamstring tendon autografts. BMC Musculoskelet Disord 19:363

37. Burns EA, Collins AD, Jack RA 2nd, McCulloch PC, Lintner DM, Harris JD (2018) Trends in the body mass index of pediatric and adult patients undergoing anterior cruciate ligament reconstruction. Orthop J Sports Med 6:2325967118767398

38. DiSilvestro KJ, Jauregui JJ, Glazier E, Cherkalin D, Bennett CH, Packer JD et al (2017) Outcomes of anterior cruciate ligament reconstruction in obese and overweight patients: a systematic review. Clin J Sport Med. https://doi.org/10.1097/jsm.0000000000 000521

39. Houck DA, Kraeutler MJ, Vidal AF, McCarty EC, Bravman JT, Wolcott ML (2018) Variance in anterior cruciate ligament reconstruction graft selection based on patient demographics and location within the multicenter orthopaedic outcomes network cohort. J Knee Surg 31:472-478

40. Novikov DA, Swensen SJ, Buza JA 3rd, Gidumal RH, Strauss EJ (2016) The effect of smoking on ACL reconstruction: a systematic review. Phys Sportsmed 44:335-341

41. Brophy RH, Schmitz L, Wright RW, Dunn WR, Parker RD, Andrish JT et al (2012) Return to play and future ACL injury risk after ACL reconstruction in soccer athletes from the Multicenter Orthopaedic Outcomes Network (MOON) group. Am J Sports Med 40:2517-2522

42. Zaffagnini S, Grassi A, Marcheggiani Muccioli GM, Tsapralis K, Ricci M, Bragonzoni L et al (2014) Return to sport after anterior cruciate ligament reconstruction in professional soccer players. Knee 21:731-735

Publisher's Note Springer Nature remains neutral with regard to jurisdictional claims in published maps and institutional affiliations. 